\title{
La escritura de las mujeres: espada hecha arte*
}

\section{Women's Writing: \\ Sword Made Art}

\author{
A escrita das \\ mulheres: a arte \\ fez a espada
}

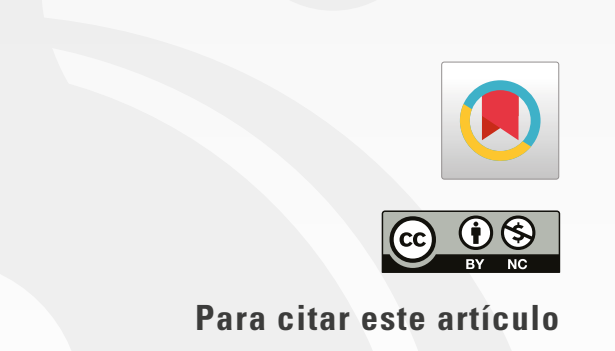

Castrillón Castrillón, S. (2021). La escritura de las mujeres: espada hecha arte. Folios, (54). https://doi.org/10.17227/folios.54-11800
* Este artículo es una reflexión producto del trabajo de tesis en curso titulado “Representaciones sobre las mujeres en el ensayo Una habitación propia, de Virginia Woolf", que la autora realiza en la actualidad en el marco del Doctorado en Educación de la Universidad de Antioquia (Colombia), abril de 2020.

* Magíster en Investigación Psicoanalítica de la Universidad de Antioquia. Profesora de la Facultad de Medicina, Universidad de Antioquia, Medellín Colombia.

Correo: sandra.castrillon@udea.edu.co
Artículo recibido $29 \cdot 05 \cdot 2020$

Artículo aprobado $28 \cdot 01 \cdot 2021$ 


\title{
Resumen
}

El siguiente artículo de reflexión surge del trabajo de tesis en curso que busca rastrear las representaciones sobre las mujeres en el ensayo titulado Una habitación propia, de Virginia Woolf (2001), en el cual se exponen algunos aspectos que ella sugirió a las mujeres escritoras. Un elemento que cruza este ensayo es la hipótesis que la autora demuestra a lo largo de su texto: una mujer debe tener dinero, espacio, independencia y libertad intelectual para dejar por escrito sus ideas. El artículo se compone de dos momentos: en una primera parte se muestran las dificultades que han tenido las mujeres en el oficio de escribir $y$, en una segunda, se señala cómo precisa situarse una escritora en dicha labor, desde lo inédito de la mirada de las mujeres que narran el mundo desde su lente. En conclusión, la escritura es el arte a través del cual algunas mujeres narran el mundo desde sus voces todavía nuevas, reinventándose a la vez, pero al mismo tiempo es el arma con el que se señala la falta de igualdad en derechos que todavía pervive.

\section{Palabras clave}

mujeres y escritura; Virginia Woolf; escritura y feminismo; habitación propia

\begin{abstract}
The following reflection article, which arises from the ongoing thesis work that seeks to track representations about women in the essay A Room of One's Own of Virginia Woolf (2001), where she exposes some aspects that she suggested to women writers. One element that crosses this essay is the hypothesis that she demonstrates throughout her text: women must have money, space, independence and intellectual freedom to leave her ideas in writing. The article consists of two moments: in the first part the difficulties that women have had in writing craft are shown and, in a second part, the article points out how it is necessary to position yourself as a writer in that work, from the unpublished look of the women who narrate the world from their lens. In conclusion, writing is the art through which some women narrate the world from their still new voices, reinventing it at the same time, but simultaneously it is the weapon with which the lack of equality is pointed out

\section{Keywords}

women and writing; Virginia Woolf; writing and feminism; own room

0 artigo de reflexão a seguir, que emerge do trabalho de tese em andamento que busca traçar as representações das mulheres no ensaio intitulado Quarto Próprio de Virginia Woolf (2001), expõe alguns aspectos que ela sugeriu às mulheres escritoras. Um elemento que atravessa este ensaio é a hipótese que ela demonstra ao longo de seu texto: que uma mulher deve ter dinheiro, espaço, independência e liberdade intelectual para escrever suas ideias. 0 artigo é composto de dois momentos: na primeira parte, são mostradas as dificuldades que as mulheres tiveram na profissão de escrever e, na segunda parte, o artigo indica como é necessário posicionar-se como escritora no referido trabalho, a partir do inédito. olhar das mulheres que narram o mundo através de suas lentes. Em conclusão, a escrita é a arte através da qual algumas mulheres narram e reinventam o mundo com suas vozes ainda novas, mas ao mesmo tempo é a arma que aponta à falta de equidade
\end{abstract}

Abstract that still lives on.

\section{Resumo} em direitos que ainda vivenciam.

\section{Palavras chave}

mulheres e escrita; Virginia Woolf; escrita e feminismo; quarto próprio 
¿Qué les damos de comer a las mujeres artistas?

WOoLF (2001, p. 74).

\section{Introducción}

Cuando a Virginia Woolf (2001) le pidieron que escribiera sobre las mujeres y la novela, se puso a pensar en ello y dedujo que eran variables muy difíciles de colegir: las mujeres, como sujetos en su particularidad, o como personajes de la literatura de los hombres, o como escritoras de sus propias obras, o todo ello en su conjunto. Eligió un elemento que al parecer era su opinión sobre los tres temas y que los contenía a todos: el tener; "que una mujer debe tener dinero y una habitación propia para poder escribir novelas" (p. 10) y prometió que luego mostraría cómo ese tener iba a decir mucho sobre las mujeres y la novela, especialmente si contaba cómo llegó a esa opinión sobre la habitación y el dinero: “Quizá si muestro al desnudo las ideas, los prejuicios que se esconden tras esta afirmación, encontraréis que algunos tienen relación con las mujeres y otros con la novela" (p. 10). Una habitación propia es el recorrido que hace Woolf sobre cómo llegó a la conclusión según la cual, para que las mujeres escriban, deben tener dinero y una habitación propia. El tener es la clave, tanto materialmente como en otros ámbitos.

Me propongo entrar a la Habitación de Woolf y escuchar lo que ella tiene para decirle a las mujeres escritoras, mostrando en primer lugar las dificultades que han tenido sus antecesoras en este oficio, pero así mismo cómo el arte de escribir les ha permitido llegar a los lugares que ocupan hoy en día y, en segundo lugar, de qué deben comer y beber las escritoras. Cómo dar continuidad al cometido de unas mujeres que antecedieron esta posibilidad. Si bien Una habitación propia es el recinto a partir del cual elaboro estas reflexiones, acudiré a algunos autores que permitan también comprender la dimensión de la escritura de las mujeres a través del tiempo.

\section{¿Tenemos tradición las escritoras?}

A la tibieza de esa habitación también se allega la gelidez de la realidad cuando Woolf recuerda que es muy corta la historia de las mujeres escritoras. No hemos estado allí desde el principio de los tiempos, con la consistencia con la que ha estado el hombre. Cuando ellos publicaban sus escritos, nosotras no sabíamos leer ni escribir, y la que había osado aprender y se sentaba a tejer las palabras, era reprendida en esa osadía (p. 69). Ahora, la época en la que escribe Virginia Woolf no le permite rastrear de manera amplia el recorrido de las mujeres escritoras, como sí lo hace el trabajo de las investigadoras y los investigadores hoy en día; pero, por ellas y ellos sabemos que las mujeres escriben desde el siglo vi a. C., como es el caso de Safo, pasando por Hiparquia de Atenas (siglo III a. C.), hasta la revolucionaria Pizan, con La ciudad de las damas (siglo xv) (Pérez-Garzón, 2011, pp. 25-30). A pesar de que las mujeres eran excluidas de la formación intelectual, surgen en el medioevo autoras teatrales, juglarescas o trovadoras (Sánchez, 2019, p. 207). Es posible también vislumbrar la historia de la escritora Hildegard von Bingen, gracias a que Ethel Smith (Bollmann, 2011, p. 42) nos recuerda cómo la religiosa en el siglo xiI recibió el aval del cielo para escribir todo aquello que oía y observaba. Es preciso señalar cómo surgen estas escritoras en tanto excepciones, brotando con grandes saltos en el tiempo, cobijadas a través del misticismo o la religión para poder escribir. Lo hicieron, pero bajo el sello de la excepción, de pertenecer a unas pocas que desafiaron los imperativos de la época.

No era plausible que escribieran, pues no tenían aprobación, educación ni recursos. La mujer estaba destinada a ser ese espejo que Virginia Woolf (2001) llama del doble del natural, que los hombres han necesitado para poder creerse el doble de superior que creen ser. Si la mujer era puesta en este lugar de servilismo y de espejo, ¿cómo era posible que se pusiera a escribir? (p. 50). Y cuando, a pesar del dique impuesto a sus dedos de escribiente, lo hizo a escondidas, a hurtadillas, su nombre fue ocultado 
y aprovechado por algún esposo o familiar que hizo carrera a sus expensas. El cine ya lo ha señalado en esta contemporaneidad (Runge, 2018), y antes del cine lo hizo también la escritora gallega Rosalía de Castro, quien, mostrando otra manera de no reconocer la autoría de las mujeres, en una carta dirigida a una amiga que aspira a convertirse en escritora, le advierte la incredulidad que el mundo va a dirigirle en adelante, pues supondrán que es su marido el que le escribe lo que ella firma (De Castro, 1996). Woolf (2001) lo expresó de esta manera:

Sin embargo, cuando leemos algo sobre una bruja zambullida en agua, una mujer poseída de los demonios, una sabia mujer que vendía hierbas o incluso un hombre muy notable que tenía una madre, nos hallamos, creo, sobre la pista de una novelista malograda, una poetisa reprimida [...]. Me aventuraría a decir que Anon, que escribió tantos poemas sin firmarlos, era a menudo una mujer. Según sugiere, creo, Edward Fitzgerald, fue una mujer quien compuso las baladas y las canciones folklóricas, canturreándolas a sus niños, entreteniéndose mientras hilaba o durante las largas noches de invierno. (p. 69)

Tampoco tenían la posibilidad de ser dueñas de sí mismas, de decidir en qué momento deseaban ser esposas o madres o si, por el contrario, se dedicaban a la contemplación del mundo y a envolver esas observaciones en valiosas frases literarias. Era imposible que una mujer hiciera esto antes del siglo $\mathrm{xx}$, ya que su padre decidía cual habría de ser su destino. Vale la pena repetir que alguna mujer marcó la excepción en cuanto a estos designios, con las consecuencias que sin duda le traía esta tergiversación al orden impuesto. Gertrudis Gómez de Avellaneda fue una escritora que se impuso como un ejemplo, que marcó la diferencia cuando se negó a casarse con el hombre que le habían impuesto (González, 2018, p. 38).

Desde el principio de los tiempos, uno de los dos sexos hubo de adherirse a esa construcción de ser mujer que la cultura, hecha por hombres, había diseñado para ella y que las ató de manos y pies a unas designaciones de grandes restricciones (De Beauvoir, 2011, p. 16). La elección personal, esa posibilidad por la que interrogamos a esas mujeres desde este presente, reprochándoles el no haber optado por otras opciones, no era tan plausible en una sociedad que las ahorcaba cuando se atrevían a volverse activas en la petición de sus derechos. La historia no es tan lejana, si volvemos la cabeza al siglo XVIII para reconocer a Olimpia de Gouges, escritora pionera, quien se la jugó a muerte cuando a través de la escritura y de sus proclamas se atrevió a interrogar ese sistema instaurado. Fue silenciada para siempre en la guillotina, al lado de sus compañeras de lucha (Pérez Garzón, 2011, p. 46).

Los hombres decidían el destino de las mujeres, por cuanto se las consideraba inferiores en todos los aspectos, hasta entrado el siglo xx. Virginia Woolf señala cómo la literatura de los poetas y los dramaturgos las ensalzó al describirlas con personalidades y genios resolutivos, que contrarrestaban con la pasividad que caracterizaba a las mujeres a lo largo de la historia. No obstante esta sorpresa que expresa Woolf ante la concepción de las mujeres en la literatura de los hombres, y si bien es cierto que esos personajes no carecían de personalidad, también es preciso señalar que son duramente castigadas por esa sublevación que el mismo poeta les hace pagar tan caro. Justamente la valentía de ese temperamento teje la tragedia cuando la ley las llama a ocupar de nuevo sus lugares en los órdenes establecidos: Antígona, Fedra o Madame Bovary sufren en carne propia la sublevación llevada a cabo.

Reflexiono aquí, a través de esa frase tan gastada, que cuando se dice poéticamente que la mujer es un enigma para el hombre, probablemente asistamos más bien a la necesidad del hombre de seguir nombrándola como enigma, en aras de no reconocerla como su par, su igual, una persona perfectamente capaz de adquirir habilidades para vivir y para crear, borrándosele sus características a través de ese halo de misterios y engaños. Hoy muchos discursos académicos la siguen envolviendo en teoremas y ecuaciones que la reducen a un menos, 
en el pleno discurrir del siglo $\mathrm{XxI}^{1}$ (Freud, 1978). El saber médico a su vez, que se apuntalaba en lo que se denominó las ciencias del hombre, desde los inicios del siglo XviII, se ocupó de delinear a las mujeres con unas propiedades biológicas que centraban sus desempeños en la maternidad y la domesticidad (Pérez Garzón, 2011, p. 58). Galeno, mediante la doctrina hipocrática y aristotélica, sostuvo hasta la ilustración que la mujer era un hombre imperfecto (Pedraza, 2011, p. 75), recursos todos estos, que procuraron revertir iniciativas en pro de reconocer en las mujeres su autonomía y capacidad de construcción.

Por favor, volvamos a escribir la historia de las mujeres, pide Woolf (2001), a un auditorio de jóvenes universitarias ${ }^{2}$ porque de ellas no se ha sabido a través de la pluma de las mismas. Para que se pueda saber con claridad sobre las costumbres de las mujeres en adelante, ya que es tan difuso y falto de recursos bibliográficos, conocer sobre las mujeres de antaño, antes del siglo XVIII (pp. 122-123), excepto por los retratos pintados o escritos de los hombres.

$\mathrm{Al}$ respecto (Ramos, 2003) vuelve a recordar que la historia de las mujeres estaba redactada antes de que ellas pudieran salir del analfabetismo; esto es, ha sido escrita por el otro, antes de acceder por sí mismas a la lectura y a la escritura. Cuando por fin pudieron hacerlo, sus textos fueron negados $y$ prohibidos, una y otra vez (pp. 23-24). De allí que Virginia Woolf recurra a la fabulación que nos lleva

1 El psicoanálisis todavía nombra la construcción subjetiva de la mujer desde la lógica de la ecuación freudiana, donde ella figura como un menos, comparada con el tener fálico del hombre, tema abordado en la conferencia 33 de Freud (Freud, 1978). Los teóricos actuales muestran cómo esas ecuaciones ilustran la lógica de la castración, tanto para el nombre como para la mujer, invitándonos a pensar que se trata de unas posiciones masculina o femenina, donde puede ubicarse tanto un hombre como una mujer. Es decir, un sujeto ubicado en posición femenina no refiere necesariamente a una mujer, podría hablarse allí de un hombre, así como una mujer podría situarse en posición masculina. Lo que habría que interrogarle al psicoanálisis es por qué preserva esas denominaciones, donde lo pasivo es lo femenino, sin importar quién se ubique allí, y lo activo es lo masculino (Wright, 2004, pp. 34-40).

2 La habitación propia es originalmente el escrito de dos conferencias dirigidas a las estudiantes de la sociedad literaria de Newham y la Odtaa de Girton, instituciones femeninas pertenecientes a la Universidad de Cambridge (Woolf, 2001, p. 7). hasta ese tiempo remoto de Shakespeare, la época Isabelina del siglo XVII. Se imagina qué pasaba con la hermana del dramaturgo que también, como él, quería escribir, que quería viajar a Londres, hacer teatro. Y se figura la aventura de Judith, así es como la nombra, esa chica que se aventura a ir a Londres para mostrar sus escritos a los directores de teatro. ¿Corría con la misma suerte del hermano? No. Terminaba burlada por sus intentos de escribir, tal como ocurrió efectivamente con las muchas escritoras de aquella época, cuando los hombres que se consideraban importantes académicamente vociferaban que las mujeres no estaban aptas para escribir (Woolf, 2001, p. 75). Esas opiniones se publicaban en folletos o revistas de aparición periódica y las chicas crecían leyendo estos veredictos sobre ellas y sus posibilidades de escribir o desarrollar algún arte. Pérez Garzón (2011) nos relata que a comienzos del siglo XIX un socialista utópico, Sylvain Maréchal, trabajador de la igualdad humana, por lo demás, publica no obstante un folleto titulado Proyecto de una ley prohibiendo aprender a leer a las mujeres, reeditado a finales del mismo siglo (p. 67). Esto es, una propuesta y publicación contemporánea a la escritura de estas primeras mujeres literatas.

Parafraseando a Woolf (2001), era tan imposible escribir en aquella época para una mujer, que, si hubieran tenido el talento y las agallas, se hubieran vuelto locas (p. 68). Dañaba poseer la magnífica prebenda de mirar el mundo de cierta manera, de la manera en que solo el artista puede verlo y a su vez devolverlo por escrito, esa virtud llamada talento era una maldición para una chica obcecada en ser una con la pluma y el papel. Tanto esfuerzo en esquivar y defenderse, hacían que algunas cayeran derrotadas. Charlotte Brontë no lo soportó: un don maravilloso, un talento a flote y, no obstante, la perseguía la necesidad constante de dolerse de su situación constreñida a la visión de unos campos, sin poder ir más allá. Pero en esas situaciones vivían $y$ trabajaban en su arte las mujeres de ese tiempo. Aun así, se dieron el lujo de apropiarse y fortalecer el género de la novela. Desde aquí, desde este presente, distingo a Jane Austen, que se sentía aliviada 
de escuchar el crujir de los goznes de la puerta del salón a la entrada de alguien, porque ello le permitía esconder su escritura, nos cuenta Woolf, casi divertida, admirada de esta mujer que supo sortear esos discursos aplastantes y tan solo fue fiel a sus dictados íntimos (Woolf, 2001, p. 94).

Estas dificultades secundaban entonces que no existiera un estado mental muy propicio para crear. Y, aun así, el loto se embebió de lodo y creció agarándose de sus límites. Será porque justamente la escritura, como lo dice Woolf en uno de sus escritos autobiográficos, da cuenta de cómo los golpes se transforman en dodecaedros que hacen obras de arte (Woolf, 2008, p. 93). A pesar de la brevedad de la historia en cuanto a esta escritura de las mujeres, el gran legado consistió en que se arara un camino en el que esas diseñadoras de palabras marcaran la impronta. Se fundó la posibilidad de que las mujeres escribieran en adelante. Las escritoras que cita Woolf en los capítulos cuatro y cinco de su texto Una habitación propia (2001) no solamente escribieron, sino que interrogaron, se dolieron y buscaron vías de salida para dar expresión a lo que consideraban que tenían que decir y demostraron cómo podían ganar un sustento económico con esa decisión. Incluso aquellas que claudicaron, porque, antes de encerrarse en sus páramos y sus parques, contaron en medio de la desazón por qué dolía tanto escribir sitiadas por la multitud de voces que les increpaban “escribir? ¿Para qué quieres tú escribir?” (p. 74).

Pero antes del siglo XVIII, como se ha venido diciendo, no se había iniciado una tradición de mujeres escritoras. "Porque, si somos mujeres nuestro contacto con el pasado se hace a través de nuestras madres" (Woolf, 2001, p. 104), pues no había madres en la literatura de que aferrarse, qué sendero seguir. Y la huella que se proponía como ruta posible era muy distante para convertirla en guía, tal como lo ilustra Woolf, al señalar los únicos vestigios existentes de los que hubieran podido servirse las narradoras:

El peso, el paso, la zancada de la mente masculina son demasiado distintos de los de la suya para que pueda recoger nada solido de sus enseñanzas. El mono queda demasiado lejos para ser de alguna ayuda. Quizá lo primero que descubrió la mujer al coger la pluma es que no existía ninguna frase común lista para su uso. (Woolf, 2001, p. 105)

En la escritura existía y ha existido cierta universalidad, un modo de narrar que ha sido tradición de los hombres, expresiones que les incumben a su sexo, a sus intereses, a sus objetivos y desarrollos históricos en los que la mujer no ha tenido cabida hasta entrado el siglo xx (Woolf, 2001, p. 105). Como no ha sido un terreno de las mujeres, esas frases, esos puntos comunes, no se acomodan a lo que ellas quisieran nombrar. Al respecto, De Lauretis (2000) dice que ha habido el lenguaje de los hombres y el silencio de las mujeres; los hombres con acceso a decirse y decir el mundo, las mujeres relegadas al silencio y a la expresión del hombre que hablaba por ellas. Un silencio que, no obstante, para algunas, se empezó a sostener en la escritura, es decir, ellas no empezaron a objetar hablando, sino escribiendo (De Lauretis, 2000, pp. 14-15). Esto es, en la historia, las revoluciones que las mujeres llevaron a cabo, en cuanto a la lucha por la igualdad de derechos, fueron sostenidas a través de la escritura, porque no tenían acceso a la pronunciación de un discurso en cuanto estaba prohibido que participaran en actos políticos públicos (Pérez Garzón, 2011, p. 48). Tampoco en lo privado su voz tenía posibilidades de alcanzar consecuencias, excepto el del acallamiento brutal. Escribir es un acto muy silencioso, de hecho, requiere silencio, aunque el estruendo sea póstumo a ese hacer, y traiga consecuencias indelebles, la tinta guarece de la expresión de cualquier olvido.

De Lauretis (2000) hace una bella pregunta por el nexo entre la escritura y el silencio. En tanto no se ha hablado de la mujer, en la historia ella no tiene cabida en el lenguaje, entonces ¿ella cómo se nombra? De Lauretis propone una reinvención, se debe hablar el lenguaje de los hombres y el silencio de las mujeres, ya que es en ese lenguaje ajeno donde existimos, pero se deben buscar estrategias de discurso que otorguen voces al silencio de las mujeres, "dentro, a través, contra, por encima, por debajo y más allá del lenguaje de los hombres" 
(p. 18). Inventar a partir de lo que hay y no hay. Después de la queja, del señalamiento al vacío y a lo no otorgado, hay que pasar a la invención y a la edificación. Nombrar lo inexistente creando, dos tareas en una misma obra, esto es, el texto literario es invención, juega allí la fantasía, lo artificioso, pero cuando lo escribe una mujer a la vez se inventa ella en el lenguaje porque está inaugurando una manera de decir cómo ella ve el mundo, cómo se mueve en él. Inventa y se inventa. Pero la invitación de Woolf (2001) es a ir más allá de las propuestas literarias existentes e inaugurar nuevos formatos para escribir, además de los que ya se tienen:

Pero todos los géneros literarios más antiguos ya estaban plasmados, coagulados cuando la mujer empezó a escribir. Solo la novela era todavía lo bastante joven para ser blanda en sus manos, otro motivo quizá por el que la mujer escribió novelas. $\mathrm{Y}$ aun quién podría afirmar que "la novela" (lo escribo entre comillas para indicar mi sentido de la impropiedad de las palabras), ¿quién podría afirmar que esta forma más flexible que las otras sí tiene la configuración adecuada para que la use la mujer? No cabe duda que algún día, cuando la mujer disfrute del libre uso de sus miembros, le dará la configuración que desee y encontrará igualmente un vehículo, no forzosamente en verso, para expresar la poesía que lleva dentro. (p. 106)

Ya no tenemos que escribir dentro de los géneros que nos han señalado, esos que estaban antepuestos a nuestra escritura, de los que también podríamos servirnos, si como renglones nos son propicios al decir. Pero es auténtico que la escritora se pregunte: ¿Cómo es la forma por la que debe de pasar el silbido que se quiere emitir?, ¿cómo son las sinuosidades del espacio, es alargado o es ancho, requiere continuidad o va apareciendo según el tono de esa melodía que nos dictamos? Esto es, preguntas por la estética, por la forma, por los contenidos. La arquitectura de las frases, la armazón lógica de la escritura, que Woolf (2001) llama andamios, domos, fue una invención del hombre. La recurrencia de unas frases, el comienzo, medio y final de las historias, la ortografía, la acentuación, le eran desconocidas a la escritora primigenia que se desperezaba de su sueño uterino. Había una "escasez e impropiedad de los instrumentos", el bisturí no concordaba con el puño, el agarre de la pluma no era posible porque ella no presenció el origen de la pluma (pp. 105-106).

La escritura de esas mujeres antecesoras del siglo XIX se caracterizó además por ser íntima, emocional, justamente porque era ese el contexto en el cual existían: interiores, salones de reuniones familiares, habitaciones compartidas, la cocina y los espacios destinados al hacer doméstico y al cuidado de los niños. No viajaban, no conocían el mundo, no iban solas por las calles, no tenían acceso a la educación y a esas discusiones académicas con pares. Por tanto, su escritura estuvo teñida de ese distanciamiento del mundo, de esa soledad, ese malestar y resentimiento, que no deja trabajar adecuadamente las situaciones, los personajes, los ambientes en un texto literario. El rencor, la apatía, la expulsión de la rabia entraban a ganarse un lugar principal en los escritos de aquellas autoras. Acerca de Brontë, dice Woolf (2001):

[...] pero si uno las lee con cuidado, observando estas sacudidas, esta indignación, comprende que el genio de esta mujer nunca logrará manifestarse completo e intacto. En sus libros habrá deformaciones, desviaciones. Escribirá con furia en lugar de escribir con calma. Escribirá alocadamente en lugar de escribir con sensatez. Hablará de sí misma en lugar de hablar de sus personajes. (pp. 96-97)

La crítica de Woolf para con ellas es comprensiva, por cuanto una y otra vez, mientras las reconoce en su desnudez, le recuerda a quien lee que no estaban en cualquier contexto, no estaban autorizadas ni para escribir, ni para pensar, ni para opinar. Se arrastra un fuerte legado de desposesión, de desmiramiento: un bebé en Roma, acabado de parir, en los siglos I y II, era expuesto a ser tirado a la calle si el padre no lo levantaba de su lecho de nacimiento, la madre allí no tenía ningún tipo de validez, a pesar de haberlo gestado y parido. Pero si ese ser humano acabado de llegar era una niña, solía ser expuesto al abandono con bastante frecuencia, por decisión del padre que veía en la crianza de las mujeres un fútil esfuerzo (Aries y Duby, 1990, p. 23). Hasta el siglo 
XIV los hombres estaban decidiendo si consideraban a las mujeres humanas o no, y justamente una mujer escritora se lanzó al ruedo de la discusión a través de un libro de su autoría, la lejanísima Christine de Pizan (Pérez Garzón, 2011, p. 30). El dedo de Woolf señala a las guerreras, a las escritoras, en una tierra baldía, donde el rasguear de un puño femenino sobre el papel era blasfemia. Nos pellizca sobre lo que no debe hacerse al escribir, como mujeres, nos pule el arma a quienes ostentamos hoy otras luchas.

Y quizá una de las luchas que haya que librar sea lo que ella llama "el efecto del sexo sobre el novelista", esto es, lo subjetivo arrastrando la historia a cuestas, interponiendo en primer plano el dolor, que tiene una lógica y una verdad, pero que estorba si con él no se hace arcilla adecuada para la escultura de la narración. Las mujeres han sostenido a la humanidad, esto es, han cargado con la preservación de la vida a cuestas, pues son ellas las señaladas una y otra vez para cuidar de aquellos que lo requieren como los niños, los enfermos, los desvalidos, los hombres en general. Han sido señaladas, quizá por la coincidencia de su organismo en propiciar la vida desde su útero, para hacerse cargo de la intimidad de lo doméstico que es lo que propicia que exista cultura y civilización. Llevan en sus espaldas, a la manera de ese Atlas Farnesio, la edificación de un mundo donde ellas subsisten, so pena de hacer existir el mundo.

Pero ¿qué puede hacer con eso ahora? Otra vez De Lauretis (2000) lo recuerda: reinventar, dar una zancada nueva, diría Woolf, beber de los lugares conquistados. Porque si el dolor se vuelve persecutorio, entonces las mujeres escribirán sobre unos textos que no dejaran emerger otros dichos, las opiniones nuevas, la mirada fresca, asombrada, de lo que tiene que decir una mujer que no había dicho y que ahora puede empezar a decir desprendida de autoridades que le digan cómo, de opiniones ajenas a ella (p. 18).

En el tiempo en que Virginia Woolf (2001) escribe Una habitación propia, 1928, los estantes de su biblioteca contenían libros de mujeres y hombres casi por igual, aunque señala su duda y deja esbozado que es posible que la diferencia en ello todavía se balancee a favor del varón (p. 109). No obstante se regocija con los diferentes géneros y temas que logra contemplar del lado de la escritura de las mujeres, pasando de la queja a la exploración del mundo, a la contemplación y al hacer de esa introspección. En su biblioteca, donde ha proseguido su investigación acerca de por qué las mujeres hasta el siglo XIX escribieron tan poco y los hombres casi todo, hace un llamado a esa corta historia de las escritoras y desde allí también dilucida algunas recomendaciones para las escribientes del ahora.

\section{¿Qué estado se requiere para que una mujer escriba?, ¿de qué debe comer y beber?}

Para comenzar, ¿qué características debe tener esa escritura, qué formas, qué diámetros? Woolf (2001) dice que cada una debe inventar esa manera propia, pero ella, siendo conocedora de la desigualdad en cuanto a roles y responsabilidades que todavía tiene una sobrecarga en las mujeres, suelta de soslayo:

El libro tiene que adaptarse en cierto modo al cuerpo y, hablando al azar, diría que los libros de las mujeres deberían ser más cortos, más concentrados que los de los hombres y construidos de modo que no requieran largos ratos de trabajo regular e ininterrumpido. (p. 107)

Hasta la complexión del libro hubiera requerido su singularidad, en el siglo xx y en este siglo xxI, donde todavía las mujeres asumen roles domésticos que obligatoriamente deben compaginar con su escritura. Cabe decir que a pesar de las ganancias que tienen las mujeres en este siglo xxI, todavía grandes diferencias subsisten, no está muy lejos el tiempo, 2013, en el que la ganadora del Nobel, Alice Munro (citada por Torres-Duarte, 2013), le contaba a la prensa su osadía de escribir mientras era madre:

En esos años nacieron sus tres hijas, y Munro, disciplinada, escribía mientras tomaban las siestas, entre una y tres de la tarde. Luego, cuando crecieron, escribía en cuanto se iban al colegio, y en las tardes retomaba el trabajo en casa. Había ocasiones en que escribía con una mano y con la otra acariciaba a la bebé en la cuna. 
Los derechos de las mujeres y las conquistas en dicha igualdad parecen servidas a la mesa, pero ello no quiere decir que puedan ir a comer y beber de ese manjar tan fácilmente. A mi manera de ver, solo es cuestión de echar un vistazo a la todavía estructura familiar y a su funcionamiento para caer en la cuenta de que todavía se preservan las funciones que otrora se tenían destinadas a la mujer, como el cuidado de los niños, del marido y el mantenimiento del hogar en general, a pesar de que trae a casa el mismo rubro económico que su compañero. En muchos casos, su trabajo se ha multiplicado.

Considero que, en este tiempo actual en el que los hombres y las mujeres estamos presentes para realizar y presenciar los cambios, materializando la igualdad de derechos, deberían acogerse esas singularidades de la escritura según la particularidad de cada persona, independiente de su sexo, más bien en beneficio de sus necesidades como escritora o escritor. También es cierto que las mujeres hemos ganado terreno en otros roles, en otras funciones y la independencia económica nos permite distanciarnos de las antiguas funciones asignadas, las etiquetas y las imposiciones que hacen tan difícil el hacer literario, entre otros. Woolf llama a la responsabilidad de cada una en este tiempo en que hay elementos para cambiar los escenarios, la decisión personal empieza a ser más viable que antes. Siempre habrá que reconocer los impedimentos que todavía obstaculizan, pero el empedrado es distinto, esto es, el forcejeo por la igualdad de derechos tiene rutas más viables.

Virginia Woolf exhorta a las mujeres a hacer un silencio sincero, introspectivo y a reflexionar sobre la propia manera de percibir el mundo. Cuando, en su búsqueda, se encuentra con el libro de Mary Carmichael, el nombre de una escritora que al parecer inventa ${ }^{3}$, señala lo novedoso y asombroso

3 Este nombre, al parecer inventivo, coincide con el de Marie Charlotte Carmichael Stopes. Autora, feminista y científica británica, contemporánea de Virginia Woolf, profesora universitaria, fundadora de la primera clínica de planificación familiar. Podría suponerse que Virginia Woolf tuvo contacto con ella y con sus avances científicos o tuvo noticia de su trabajo. Esta mujer defendió la libre sexualidad de las mujeres, por lo que propendía por la anticoncepción (Pérez Garzón, 2011, p. 156). que resulta cuando una mujer escribe sobre temas que solo han sido del dominio de los hombres, como la sexualidad. Cómo la vivencian ellas, qué cosas no han sido dichas, qué temas no han sido tratados, puesto que la sexualidad de las mujeres ha sido escrita, fotografiada y filmada desde el ojo masculino. Pide que hagamos silencio y miremos el relato de esta escritora en espera de que ella pueda comunicárnoslo. Cómo describe una mujer el lesbianismo, cómo narra su encuentro sexual con un hombre, cuáles son las maneras en las que dirá sobre lo que ella considera que es el amor. Las mujeres, más allá de ser las amantes y objeto sentimental de los hombres, cómo son cuando son amigas, luchadoras, enemigas, crueles, valientes ${ }^{4}$.

Era extraño que, hasta Jane Austen, todos los personajes femeninos importantes de la literatura no solo hubieran sido vistos exclusivamente por el otro sexo, sino desde el punto de vista de su relación con el otro sexo. Y esta es una parte tan pequeña de la vida de una mujer... Y qué poco puede un hombre saber siquiera de esto observándolo a través de las gafas negras o rosadas que la sexualidad le coloca sobre la nariz. De ahí, quizá, la naturaleza peculiar de la mujer en la literatura; los sorprendentes extremos de su belleza y su horror; su alternar entre una bondad celestial y una depravación infernal. (Woolf, 2001, pp. 113-114)

El hombre estaba solo narrando el mundo, tratando de fotografiarlo desde la única cámara fotográfica que existía. Por un lado, le era beneficioso, porque a partir de esa escritura delineaba los contornos del universo y trazaba unas indicaciones del deber ser de la mujer. Por otro lado, la mostraba como su percepción la suponía: sagaz, intrépida, un cierto perfil que solo tenía cabida en esa escritura ambivalente, como lo muestra Woolf.

4 Desde mi perspectiva, el cine está mostrando esas caras de las mujeres en la actualidad, especialmente en los dibujos animados, lo que es muy bien recibido, porque esas chicas valientes que escapan de torres por sí mismas, son heroínas a través de sus propios méritos, no pasan años a la espera de un príncipe rescatante, y se hacen a sus propias victorias, alimentan las nuevas concepciones de las niñas el día de hoy. En esa misma vía avanzan la literatura y las artes en general. 
También va a decir Virginia Woolf (2001) que será fabulosa la riqueza que se obtendrá en la literatura cuando los dos sexos estén narrándose y describiéndose mutuamente, mostrando esa parte del otro que el otro no alcanza a ver, ese punto del tamaño de un chelín que está detrás de cada cabeza y que uno agradece cuando el otro habla de él (p. 123). De ahí la invitación que ella hace a los dos sexos, de mirarse y relatarse, mediante la observación limpia, grandilocuente de la escritura, pero sin el enredo de la queja y el rechazo. Sin el intento cavernícola de aspirar a la superioridad de uno sobre el otro. Pero, que advenga, con paso firme, lo que las mujeres tienen que decir de ellas y del mundo:

Porque quería ver cómo se las arreglaba Mary Carmichael para captar estos gestos jamás plasmados, estas palabras jamás dichas o dichas a medias, que se forman, no más palpables que las sombras de las polillas en el techo, cuando las mujeres están solas y no las ilumina la luz caprichosa y colorada del otro sexo. (Woolf, 2001, p. 116)

Woolf (2001) recomienda hacer uso de lo que ella llama "la fuerza sumamente compleja de la feminidad" (pp. 119-120), que es un modo de poner afuera las concepciones de las situaciones íntimas, con las que la mujer se ha relacionado hasta el momento, la relación con los objetos que le son próximos, la lectura interior de ese contexto que hasta hace poco fue tan reducida: el mundo de la domesticidad. Woolf dice que la escritora tiene que iniciarse en la escritura como hizo con esos acontecimientos que la requerían, con esas estancias, con esas paredes, con esos niños de sus vientres, con esos esposos a los que su sola presencia avivaba el fuego de la creación. Tomar todo aquello y hacer arte con eso, concebir edificios, reinventar los mapas del mundo. Saber de manera contundente que a los convencionalismos se les puede decir que no, se puede objetar ser lo que no se quiere ser y seguir el hilo de la creación representado en un conejo, echar a correr, escapary tal vez luego encarar esa decisión de decir: habré de navegar por continentes, dejarse seducir, tal como le ocurrió a Alicia, por la resbaladilla imaginaria de la infancia (Burton, 2010). Retomar esa fuerza que las mujeres han empleado en esos sucesos y acontecimientos de la intimidad de lo doméstico y crear, imantar el mundo de esa fuerza en el mismo arte, en la escritura:

Basta entrar en cualquier habitación de cualquier calle para que esta fuerza sumamente compleja de la feminidad le dé a uno en la cara. ¿Cómo podría no ser así? Durante millones de años las mujeres han estado sentadas en casa, y ahora las paredes mismas se hallan impregnadas de esta fuerza creadora, que ha sobrecargado de tal modo la capacidad de los ladrillos y de la argamasa que forzosamente se engancha a las plumas, los pinceles, los negocios y la política. Pero este poder creador difiere mucho del poder creador del hombre. Y debe concluirse que sería una lástima terrible que le pusieran trabas o lo desperdiciaran, porque es la conquista de muchos siglos de la más dura disciplina y no hay nada que lo pueda sustituir. (Woolf, 2001, pp. 119-120)

Invita a realizar una combinación nueva de sus recursos altamente desarrollados para otros fines, pasado de generación en generación, para agregar lo nuevo a lo viejo, sin perturbar el equilibrio del resultado. El hacer de las mujeres, hasta los inicios del siglo $\mathrm{xx}$, tiempo en el cual Virginia escribe Una habitación propia, es difícil de historiar, de medir, de clasificar, arrastra todavía en ese momento la caracterización de unas cualidades que atañen al cuidado del otro, a la maternidad, a logros que no son posibles de medir ni social ni culturalmente. "No hay ninguna marca en la pared que mida la altura exacta de las mujeres" (Woolf, 2001, p. 117). Pero, cómo apropiarse de esas dotes de minucia, dedicación y edificar obra en adelante. Cómo hacer uso en la escritura de la obsesión de la organza y el tejido, de la intervención que día a día se daba a unas habitaciones, la entrada de la luz, la recurrencia a inventar los ambientes, cómo ponerlo al servicio de otras creaciones. Lo que sugiere Woolf es no sustraer esa filigrana que adviene de esa particularidad de las mujeres entrenadas desde los inicios de la humanidad para servir al otro, sino más bien hacer uso de esa singularidad, de esa entrega del detalle de fraguar cobijo, la cocción del alimento, el bienestar de sus 
hijos, la entrega a su cónyuge y ponerlo al servicio del forjamiento del mundo desde al arte, la cultura, la invención. Es muy textual cuando Woolf les señala a las mujeres que la maternidad es una opción, pero que no se convierta en un número desmedido que no deja la posibilidad de otras salidas y otras creaciones (2001, p. 152). Y expandir esa peculiaridad, salir de esas habitaciones y de otras habitaciones y alargar la mirada cuanto sea posible.

No buscar la igualdad más que en los derechos, ciudadanos con igual derecho a construir su particularidad sean hombres o mujeres. Woolf puntualiza que sería un desperdicio que la escritura de las mujeres busque parecerse a la de los hombres, con la necesidad que tenemos de leer la diversidad de miradas sobre la existencia. Le parece a ella que el ser distintos no es el problema, que dos sexos, ya son muy poco. Vale la pena repetirlo: cada uno ya es distinto, se trate de un hombre o de una mujer, la escritura de cada uno debe ser concebida desde la mirada única que la persona le dirige a la realidad, en pro de obtener esa multiplicidad de realidades. Sin duda Virginia Woolf hace hincapié en eso tan distinto y aunque se repita tanto en este escrito, vale la pena el ahínco, en eso tan distinto que la mujer tiene para decir porque no ha dicho, porque apenas se entreabren sus dedos al teclear y transmitir lo que le susurra el existir. Ser receptáculo de esa realidad y ser fiel a la manera como se recibe esa realidad, ser ferviente a la percepción propia. Por eso tiene que buscar a toda costa su propia manera de decirlo, sin intentar rastrear tonos ya hechos que no le van.

Habrá que decir también que la vida actual de las mujeres, esos giros contemporáneos, son dignos de contar: mujeres que se divorcian, que contraen nupcias varias veces, que deciden tener hijos por voluntad propia o que toman la decisión de no tenerlos definitivamente. Mujeres que no se casan, que viven solas, o con un perro, mujeres que se enfrentan a desafíos profesionales inauditos y maravillosos, viajeras que recorren el planeta con sus ojos a cuestas para ver y maravillarse. De todas estas invenciones habrá que escribir.
Y hay una muchacha detrás del mostrador; me gustaría más leer su historia verdadera que la centésima quincuagésima vida de Napoleón o el septuagésimo estudio sobre Keats y su uso de la inversión miltoniana que el viejo Profesor $\mathrm{Z}$ y sus colegas están escribiendo en este momento.

(Woolf, 2001, p. 123)

Virginia Woolf (2001), de la mano de la descripción que hace de su novelista fabulada, sigue trazando sus exhortaciones: "escribía como una mujer, pero como una mujer que ha olvidado que es una mujer, de modo que sus páginas estaban llenas de esta curiosa cualidad sexual que solo se logra cuando el sexo es inconsciente de sí mismo" (p. 126). La mujer auscultadora del mundo, dando cuenta de su mirada particular, puesta al servicio de la escritura. Y arremete: no hay que enredarse buscando cuál bando es mejor, si los hombres o las mujeres, si esta escritura o aquella, cada uno jalonará lo que se desprende de sí en la experiencia, e irá a beber en el otro lo que llame a su sed. Que las mujeres no desperdicien su escritura en la demostración de un más o menos, porque es imposible tal distinción. De acuerdo con ello, ¿cómo perseguir algún tipo de aprobación y sacrificar la propia voz en aras de encantar y perseguir el beneplácito?

Y de manera muy contundente amonesta: debemos tener. Para empezar, dice Woolf, tener una habitación propia. Se requiere el tiempo y los medios que brindan ese tiempo, para disponerse a escribir. Quinientas libras al año vienen muy bien y son esenciales, para que exista el espacio y el tiempo, la habitación y el tiempo, el dinero que procura la existencia de estos elementos. Me parece que, de acuerdo con esto, la mujer del siglo xxi tiene una responsabilidad enorme por estar situada en este peldaño del tiempo, en que el acceso a la educación le da la posibilidad de formarse en una profesión u oficio que le lleve a ganar sus quinientas libras. No todo está hecho, no todas las condiciones servidas ni facilitadas, pero grandes piedras han sido extraídas y su avanzar empieza a facilitarse. Es el tiempo irreversible de hacerse cargo de sí. 
Se requiere, en esta vía del tener, la autorización, que en primer lugar la mujer debe darse para esta disposición. Ahora, mi hipótesis es que esta decisión propia está mediada, muy constreñida, por la disposición de la cultura que va a asegurarle que ella no correrá riesgos de ser señalada, amonestada o asesinada si alza su pluma y deja fluir su pensamiento, como efectivamente sucede todavía a algunas mujeres en algunas partes del mundo, según ha contado la editora y escritora Esther Tusquets (2011, p. 11). Digo mediada, muy constreñida, pero no exclusiva, pues una de las dos puntas es un flanco de máxima fuerza: la decisión personal. También nos lo recuerda Virginia Woolf (2001), con la foto de Aphra Behn (p. 89), esa escritora de clase media, que tras la muerte de su marido tuvo que buscar sustento y lo encontró en la escritura. Hizo dinero escribiendo. Llevó comida a sus hijos, producto de su oficio. Que ganara dinero con ello, en aquella época, cuando era imposible hacerlo, hace que Woolf escriba: "Este hecho sobrepasa en importancia cuanto escribió... porque de entonces data la libertad de la mente... la posibilidad de que, con el tiempo, la mente llegue a ser libre de escribir lo que quiera" (p. 89).

Seguramente el empeño personal es una fuerza que al aunarse con lo que la sociedad ofrece produce genialidades, productos culturales y prácticas que vivifican una sociedad. Pero el solo empeño personal dificulta sobremanera la construcción de la obra, allá está Lady Winchilsea, la condesa que se ahogó en su propia queja y no dejó fluir la obra donde mejor se hubiera aposentado su protesta (Woolf, 2001, p. 82). Se requiere la fuerza de Aphra Behn y el contexto social que facilite su crear en vez de exigir la insufrible lucha de una heroína, que de seguro no es exigida a los escritores masculinos y que les permite a ellos escribir con mayores garantías. El talento, el trabajo y la oportunidad deberían ser los instrumentos de viaje para todos. En la actualidad aumenta el número de mujeres que escriben, aunque siguen existiendo unas diferencias muy puntuales en cuanto a las clasificaciones y evaluaciones de sus obras al interior de las editoriales (Tusquets, 2011, p. 12).

Y pide Woolf (2001): mujeres por favor escriban, es que ya he leído mucho a los hombres, escriban lo que quieran:

Espero que encontréis, a tuertas o a derechas, bastante dinero para viajar y holgar, para contemplar el futuro o el pasado del mundo, soñar leyendo libros y rezagaros en las esquinas, y hundir hondo la caña del pensamiento en la corriente. Porque de ninguna manera os quiero limitar a la novela. Me complaceríais mucho -y hay miles como yo- si escribierais libros de viajes y aventuras, de investigación y alta erudición, libros históricos y biografías, libros de crítica, filosofía y ciencias. Con ello sin duda beneficiaríais el arte de la novela. (p. 147)

Para concluir, la escritura de las mujeres, aparecida desde los cimientos de la cultura humana, se ha abierto paso, pese a los obstáculos y adversidades. Y esa escritura, que tiene ya en este siglo su tradición, ha permitido que las mujeres encuentren su manera de narrar, a partir de diferentes géneros, siguiendo el anterior consejo de Woolf: desde la poesía, la ciencia, la historia y la ya asimilada novela. Pero también sigue siendo una manera de denunciar la falta de igualdad en derechos que todavía pervive. La escritura de las mujeres todavía es arte y lucha.

Virginia Woolf nos dice algunas cosas más, interroga por lo que va a hacer cada escritora con lo que tiene en las manos, con aquello que sus antecesoras le entregaron: sus derechos, la lucha por la igualdad, esos primeros trazos viscerales conservados en museos y en bibliotecas deslumbrantes. Dejemos que las poetisas, escritoras madres nuestras, salgan de sus claustros y vivan a través de esas páginas cocidas diariamente, susurra Woolf mientras salimos de su habitación. Ya cerrada la puerta, ya encaminadas a la labor, y seguimos escuchando su pedido: dejemos que Judit, la hermana de Shakespeare, pueda por fin escribir (Woolf, 2001, p. 153). 


\section{Referencias}

Aries, P. y Duby, G. (1990). Historia de la vida privada. Taurus.

Bollmann, S. (2011). Las mujeres que escriben también son peligrosas. Maeva.

Burton, T. (director) y Todd, S. (productor) (2010). Alicia en el País de las Maravillas [Película]. Estados Unidos: Walt Disney Pictures.

De Beauvoir, S. (2011). El segundo sexo. Debolsillo.

De Castro, R. (1996). Las literatas. Carta a Eduarda. Recuperado de http://culturagalega.gal/

De Lauretis, T. (2000). Diferencias. Etapas de un camino a través del feminismo. Horas y Horas.

Freud, S. (1978). Nuevas conferencias de introducción al psicoanálisis y otras obras. Vol. 22. Amorrortu.

González, N. (2018). Revisando a Gertrudis Gómez de Avellaneda desde la historia de las mujeres. La Aljaba, segunda época, XXII, 33-46.

Pedraza, S. (diciembre de 2011). La educación de las mujeres. El avance de las formas modernas de feminidad en Colombia. Revista de Estudios Sociales, $41,72-83$.
Pérez Garzón, J. (2011). Historia del feminismo. Catarata.

Ramos, M. D. (junio de 2003). Historia de las mujeres, saber de las mujeres: la interpretación de las fuentes en el marco de la tradición feminista. Feminismo/s, 1, 19-32.

Sánchez, S. (abril de 2019). Olvidadas antes de ser conocidas. La ausencia de mujeres escritoras en los libros de texto en la enseñanza obligatoria. Revista Prisma Social, 25, 204-224.

Runge, B. (director). (2018). La buena esposa [Película]. Anonymous Content.

Torres-Duarte, J.(10 de octubre de 2013). Una carrera desesperada. ElEspectador.com. elespectador.com/noticias/ cultura/una-carrera-desesperada-articulo-451774

Tusquets, E. (2011). Las mujeres, la literatura y la peligrosidad -prólogo-. En S. Bollmann, y S. Bollmann (eds.), Las mujeres que escriben también son peligrosas (pp. 8-15). 3a. ed. Maeva Ediciones.

Woolf, V. (2001). Una habitación propia. Seix Barral.

Woolf, V. (2008). Momentos de vida. Lumen.

Wright, E. (2004). Lacan y el posfeminismo. Gedisa. 